\title{
OVERVIEW OF PROPOSED GEOTHERMAL DEVELOPMENT IN HAWAII
}

Prepared by Concerned Individuals and Organizations in Maui February 15, 1990

During the four hours of the public meeting hela by the State Department of Business and Economic Development (DBED) in Maui in November 1989, not one of the 200 persons present spoke in favor of geothermal development on the Big Island to supply power to Oahu. However, we were all sure after the meeting that the state would proceed on its course to develop the projest in spite of any public concerns. This situation we find incredible considering there are many unanswered questions on a subject of paramount importance to the economic and environmental well being of all of us. Our concerns are well expressed in the editoral of The Maui News, December 10, 1989 (Exhibit A). We wish to set the record straight with some facts from an economic, financial and utility planning viewpoint, recognizing also the potentially serious social, health and other environmental impacts.

When we first became aware of the concept of a $500 \mathrm{MW}$ geothermal power plant on the Big Island, together with an unprecedented high voltage submarine cable connection to Oahu, we did not consider it to be a serious proposal. Inherently it has to be more costly and less reliable than new oil or coal fired generation on Oahu. Meetings with both the State's Energy Division, Department of Economic Development (DBED), and Hawaiian Electric Company (HECO), revealed the driving force for this full speed ahead and damn the torpedoes approach, to be the State's determination to become independent of oil imports. Indeed both entities indicated that geothermal generation for oahu will be more expensive than conventional oil or coal fired generation. And there is no question its environmental impacts will be greater.

Those in our group with experience in the electric utility industry have never seen the development of a multibillion dollar project treated in such a cavalier manner, even for developments without the inherent. significant risks, reliability and envirommental concerns involved here. There is an almost paranoia for the state to become 'independent' of oil for electric generation, and to develop in the future instead the 'cleaner' geothermal alternative. This policy results in unsubstantiated, and in fact grossly inaccurate, statements from the governor's office as demonstrated by the news article in Exhibit $B$, which prompted the response from Jim Williamson, Kihei resident and consulting engineer. 
Before even entering into any kind of investigative program such as cable testing, drilling of wells, and above all soliciting proposals from international consortiums to Einarce and construct the project, the following considerations and prodedures should have been addressed:

1. The electric utility involved always takes change of the flanning, design and construction of a generation plant. Direction of this geothermal frogram is by a state department (DBED).

2. Before proceeding with major investigations a detailed cost estimate should be prepared by experienced cost estimators, together with a proper evaluation of all costs, including contingencies, engineering, and escalation and interest during construction. We have seen no such estimate, except a very incomplete and optimistic study by Decision Analysts Hawaii Inc., an economist firm, in February 1988. Carl Freedman a Maui economist, prepared a critique of that study which is included as Exhibit C. The State estimate of $\$ 1.7$ biliion at that time was far from detailed and underestimate major items such as transmission conversion, number of dry, replacement and reinjection wells, and cable installation. Futher, indirect costs and contingency allowances are far too low.

In response to the Decision Analyst work, Northwest Economic Associates in 1987 prepared a more documented and believable cost estimate which totalled about $\$ 4$ billion for a median assumption, and was considerably higher for the most pessimistic assumption. Based on information from both sources, and from other sources where appropriate, experience and an allocation of contingencies to reflect risk, we consider a reasonable preliminary cost estimate to be about $\$ 3$ billion (1988 level). This is comprised of $\$ 2.2$ billion for the plant and $\$ 0.8$ billion for transmission and conversion facilities. Compare this with an equivalent oil fired plant which would cost about $\$ 0.75$ billion, or $25 \%$ of the geothermal cost. It is certainly most alarming that the State is at this moment still talking in the range of $\$ 1-4$ billion, even while HECO is preparing to sign a contract for project construction.

3. Instead of preparing a detailed cost estimate HECO decided to rely on estimates contained in proposals for project financing and construction from international consortiums which are now being evaluated (one proposer is left but details are secret). Such information is definitely no substitute for a professional cost estimate. First of all the proposal terms of reference explicitly. state that the cost of geothermal power cannot exceed the utility's avoided cost. Since it is obvious that the 
levelopment costs cannot help but be considerably more than the avoided cost, a proposer will accordingly qualify its proposal, and include "fine print" which will enable it to recoup overruns through construction claims and, if necessary, legal action. This is the history of turnkey megabuck project construction, and invariably the contractor prevails. A local example on a smaller scale is $H$ Power. This is particularly true when conditions are of necessity ill defined as they are with a $300 \mathrm{KV}-\mathrm{DC}$ submarine cable of unprecedented length $(140 \mathrm{miles})$ and depth of submerger.ce (maximum 7000 feet). in combination with a major geothermal development in the most active volcanic area in the world.

It is the height of naivete to believe that a private contractor will bear all the risks unless it includes the aost of those risks in its bid which would then be noncompetitive. It is interesting that one of the Department's publications recommends the method of financing based on the approach used for the tunnel now being constructed between England and France. An unfortunate choice since that project, which has been studied for years, has now increased in cost by $\$ 3.2$ billion over the original estimate of $\$ 7.8$ billion (41\%). Also the proposers for Hawaii's geothermal project will probably spend up to a million dollars in its preparation which will not be reimbursed, a great incentive to low-ball the estimate. Of course the state taxpayer will bear the inevitable cost overruns. In fact Governor Waihee recently announced he is considering methods of state financial participation.

4. The utility should prepare an economic feasibility study, comparing the system costs with and without a proposed project, to determine the benefit-cost ratio and the impact on the rate base. There is no such feasibility report prepared either by DBED or HECO, even though Governor Waihee now states that geothermal's fate will be determined based on economic grounds. However, based on a capital cost of $\$ 3$ billion, estimated operation and maintenance costs, and an annual plant factor (output) of $80 \%$, the first year cost of power would be 12.9 cents/kwh. This compares to 6.4 cents/kwh for oil fired and 7.6 cents/kwh for coal fired generation based on the latest cogeneration information from HECO. The corresponding first year benefit-cost ratio of this geothermal development compared to a new oil-fired plant is thus about 0.5 , indicating that the development should be aborted now. And even if oil prices were to double, geothermal generation would still be uneconomical. A preliminary assessment of the impact on the rate base is that each power consumer on Oahu would pay on the average some $\$ 40$ each month extra for geothermal development. This represents about a $50 \%$ increase in power bills. 
5. Since increasing Dahu's power consumers' bills by $50 \%$ is obviously unacceptable, the increased cost due to geothermal construction over and above an oil-fired plant. and including standby capacity as discussed later, of some $\$ 2.6$ billion would be borne by state taxpayers. This equates to an increased debt of more than $\$ 5,000$ for each tazpayer.

6. Whenever possible, diversification from oil-fired to other generation sources is being practiced by most utilities throughout the world. HECO's move into a fluidized-bed coal fired plant is to be applauded. However. even countries which have no petroleum sources of their own, such as Japan and Israel, are still very dependent on imported oil for electric generation. Japan has developed a nominal amount of geothermal generation, apparently because of its concern with the environmental impact of geothermal, and has a substantial solar research program. Israel has a program of large coal fired plants and mandates solar water heating. No utility would develop alternative resources which would be a major part of it system (eg $500 \mathrm{MW}$ in the HECO system), if it meant a significant rate shock which could have a disastrous economic impact on residential and industrial consumers alike. Mainland utilities also have the same philosophy, and indeed oil and gas fired power plants remain, and will continue to be a major electris power producer throughout the country.

It should be pointed out that the full capacity of the $500 \mathrm{MW}$ geothermal plant will not be needed until at least 10 years after it enters into service, but the full cost of the cable would be incurred up front. Also because of transmission losses the plant installation will have to be $550 \mathrm{MW}$ as compared to $500 \mathrm{MW}$ for an oil fired plant, a $10 \%$ increase which is another disadvantage of this concept.

7. Consideration of a program to reduce petroleum imports to Hawaii has to take into account the overall spectrum of its use. Electric generation uses only about $30 \%$ of the state's imports; the remainder is principally used by the transportation industry. The $500 \mathrm{MW}$ geothermal installation would only contribute to about $1 / 3$ of Oahu's electric load some 20 years from now. Hence with all the disadvantages of this geothermal development it might save only some $10 \%$ of the state's oil imports, and not until the next century. However, oil for electric generation is a residue from refining at Barbers Point to produce large quantities of jet fuel, and there is an overabundance of this byproduct. Hence oil imports, and the potential for oil spills, will remain with us until the issue of transportation fuels is addressed. 
Compare this with an annual savings achieved of at least $35 \%$ by installing residential solar water heating. The State and HECO could help to achieve such savings by working for passage of legislation to mandate solar water heating on all new construction and to provide substantial state tax credits for installation in existing buildings. Further, if there is such a concern about imports. since the bulk of petroleum is used for transportation, how about DEED taking the money it is spending on geothermal development and using it for rapid transit in Honolulu? (\$2 to 3 billion would certainly helf that cause).

8. DBED and HECO should concentrate their efforts on a real program of electric energy conversation. Apart from the obvicus one of solar water heating, this program should include time of day pricing, time clocks for water heating, peak shaving (such as the Board of Water Supply's pumping load even if it requires additional water storage), efficient equipment, etc. As other utilities do, HECo could offer interest free loans to encourage these measures.

Exhibit $D$ is a report by Robert Mowris, a well known energy consultant from California. He explains how energy conservation can, and should, be applied in Hawaii instead of constructing generation such as geothermal.

9. Geothermal is not a proven safe and reliable resource in an environment such as the kiluea rift zones. Induced seismicity, principally because of reinjection of waste brine, should be a real concern for the Puna development. As Pasqualetti explains in his 1979 article "Geothermal Energy and the Environment: the Global Experience", significant microseismicity has occurred in the USA, Italy, and the Philippines (also in Iceland). It is most likely in regions with relevant natural activity such as the Big Island, and can be significant. The Denver earthquakes due to the Federal government's reinjection program had Richter magnitudes of 3 to 5. The Geysers caused magnitude 1.5 earthquakes and the Philippines has a swarm of activity up to magnitude $2+$ which happened after about a year of operation. The magnitude of such disturbances increases markedly with high production and reinjection pressures. Kiluea is the most active volcano in the world and has resulted in 70,000 earthquakes since 1962 .

Subsidence can also be significant. In New Zealand the the principal field has dropped 15 feet in 10 years, affecting pipes and drainage courses outside the well field area. 
Blowouts have occurred at most installations throughout the world, some devasting and still uncontrolled. They can occur during the dilling or production phases. Ormat experienced a blowout while drilling a well in Nevada and it was not capped for 26 days.

10. Geothermal energy is not a clean energy source from an environmental view as some would have you believe. Some of the general concerns are discussed below.

Energy dissipation by cooling towers is 5 times greater than for fossil fuel plants, and can cause climate changes including fog. There is a real concern by some scientists that emissions from large geothermal installations can contribute to acid rain in the same manner as coal fired plants.

Chemical effects include very corrosive saline fluids, and air pollution mainly from hydrogen sulphide, carbor: dioxide and radon. The principal problem is hydrogen sulphide. The Geysers for example is having difficulty meeting California ambient air quality standards of 0.03 ppm. In addition the natural concentration of hydrogen sulfide at Puna is four times the Geysers. By comparison Hawaii's limit was 0.1 , more than 3 times as much; it has now been revised to generally agree with the California requirements. Periodic venting of the gases of course results in these limits being exceeded greatly locally.

Also Hawaii's regulations allow injection of brine waste from geothermal installations as close as $1 / 4 \mathrm{mile}$ from a potable water source. ! Incredible! particularly when that discharge is into an active volcanic area full of tubes and fissures. Solids to be disposed of include arsenic, boron and mercury.

Hawaii's experimental well, HGP-A, operated for 7+ years with little control of significant hydrogen sulfide emissions in the midst of a residential area. As explained in Exhibit E, a statement by Robert Petricci a local inhabitant, with little or no enforcement by the State Department of Health (DOH). In fact there are large gaps in the air quality monotoring. Jim Williamson seriously questions the will, and ability, of DOH to enforce the newly promulgated standards in his letter to The Maui News (Exhibit F). The enclosed photographs (Exhibit G), vividly show the tree $k i l l$ and polluted settling pond. Such a brine disposal method, rather than reinjection, has been approved by DOH for driliing a large number of wells by True Geothermal. 
The State legislature recently proposed a Bill. SB 3415 , which would give credit to geothermal developers because of the supposed reduction in air pollutants from geothermal rather oil generation. We analyzed this Bill in detail and testified against it since the entire premise was flawed (Exhibit $H$ ). What was most revealing is that HECO is apparently presently discharging some four times the amounts of sulfur dioxide and nitrogen oxides it should be releasing using the same technology as California. Also the cost of cleaning up oil fired pollutants to acceftable levels is far less than for hydrogen sulfur abatement for a flashed-steam plant.

Undoubtedly geothermal energy may be harnessed with acceptable environmental impacts if there is close control on gas emissions, and there are proper procedures in place for handling steam and water, reinjection of brine and gas, solids, etc. However, there have been some miserable environmental results such as those in Mexico, even an early one in Japan, and the Icelandic installation discussed later.

Geothermal plants on the mainland are developed at a deliberate pace with a small installation first to gain experience and, in California particularly, are well regulated to reduce environmental impacts. We do not yet see the same mechanism in place in Hawaii. In fact it is interesting to note that DBED continues to hire consultants from Italy where there is little concern for air and water quality. Further we are not aware of any geothermal development in the middle of a residential area such as HGP$A$, and Ormat even if it is a closed cycle system, with the related safety, health, noise and other problems, and particularly in a highly active volcanic area with its associated seismicity.

In the binary - fluid (closed cycle) system the geothermal fluids are kept under pressure and heat exchangers are used to transfer heat from the geothermal fluid to an organic working fluid which is vaporised and drives a turbogenerator. They do not produce significant emissions of non condensable gases because the geothermal fluids are kept under pressure, except of course during well venting or accidental leaks. However, since there is no condensed steam as a source of cooling water as with a flashed - steam cycle, the closed cycle will require substantial quantities of water for cooling and makeup for evaporation. The most important, and potentially toxic, solid and liquid wastes are derived from the treatment of makeup water and discharge of cooling tower blowdown which could pollute groundwater. Of course there is always the potential for well blowouts with associated significant air pollution. 
11. The submarine cables will be laid in a trench in the ocean floor with a redundant cable in case one fails. However, this is a very seismically active area, even Maui experienced a 6.7 magnitude earthquake several decades ago. Hence a major movement which could damage a number, if rot all the cables, is very possible. Since HECO estimates repair time could be of the order of 6 months, prudent utility practice is not to rely on a one cable redundancy for reliability, but to install standby generation equal to the amount of the geothermal capacity to maintain a reliable system reserve. Hence, a total of 500MW of combustion turbines will need to be installed in Honolulu, complete with oil storage, at an additional cost of about $\$ 350$ million addition to the $\$ 3$ billion amount stated above.

World wide experience with HVDC submarine transmission points to a solid, and not oil filled cable, as the best type for the capacity and voltage proposed for the Big Island project. The installation and operation costs of a paper insulated mass impregnated cable should be lower and selection of this type also has the advantage that it would not then be necessary to make a landfall on Maui. We certainly do not want pumping plants and HV transmission towers cutting a swath through the pristine southwest region of this Island.

12. Geothermal developments are most often staged, so that experience can be gained on a smaller scale for capital and operating costs together with environmental impacts, before proceeding into a large scale development. The prudent course would certainly be for DBED and HECO to address technical, environmental and social problems in developing $a$ 10 to $15 \mathrm{MW}$ installation (possibly one unit at Ormat at a more remote location), and gaining operating experience over several years before proceeding further. This is exactly how the Geysers was developed with a $11 \mathrm{MW}$ plant in 1957. It was 20 years before the installed capacity reached $500 \mathrm{MW}$.

13. Geothermal is not a renewable resource. As an example of unforeseen difficulties, in Iceland the second unit of the 60 MW Krafla plant was not installed because of poor output and cost experience. By 1988 the first unit $(30$ MW) had only achieved $80 \%$ of its output $(25 \mathrm{mw})$ over a period of 8 years. The problems were many but resulted principally from overestimating the steam available and the difficulty in keeping wells in production. 24 wells were drilled but only 11 are currently producing. Also 11 wells squeezed off due to subsidence and seismic activity and 
had to be replaced at a cost of $\$ 11 \mathrm{million}$. Over a period of 10 years subsidence has occurred 20 times and there were 9 volcanic eruptions. Ormat on the other hand estimates drilling 7 to 9 production wells for its $25 \mathrm{mw}$ project (Iceland 24), 0 to 2 unusable (Iceland 11), and 2 to 3 injection wells (Iceland 8-10). The annual plant factor (output) in Iceland has reached only $53 \%$, as compared to California's 80-85\% up to now, with the result that power costs are way over budget. BY comparison the DBED econcmic analysis assumed $100 \%$ utilization with $1 / 3$ the number of wells.

The Iceland project is located in a volcanically active area not unlike the Big Island and similar problems are highly likely. Also that project is a poor environmental example. On the other hand the best installations on the mainland are in seismically quiet areas and are principally less efficient hot water (no steam), and can not be compared with Hawaii's field which is more like Iceland, Japan, Mexico and the Philippines.

There are other examples of low plant output. Japan's otake project drilled 5 wells but only 2 are producing. resulting in a $40 \%$ reduction in output. Italy, the pioneer in geothermal, by 1986 had drilled a total of 511 wells of which 190 were in production. El Salvador has 10 wells producing out of 28 drilled. The Geysers, north of San Francisco, is the largest geothermal installation in the world and was originally planned to have a capacity of 6000 MW. The installation has now reached less than 2000 MW and the steam supply has reduced dramatically, so that no more plants are being built, and some have been shut down or are operating at reduced capacity. Utility planners now often relate to the life of a geothermal resource being 20 to 30 years. Exhibit $I$ is a news article describing the Geyser situation. And most important, the capacity of our own HGP-A reduced from $3 \mathrm{MW}$ to $2.45 \mathrm{MW}$ in just a few years of operation, as discussed later.

The general observation of those experienced in this field is that geothermal installations in the past have often been underestimated in cost (capital and operation) and overestimated in output. Successful installations requires quite a shakedown period and contrary to popular belief the final overall cost is most times more than fossil fueled alternatives (the marginal cost once completed is generally less).

14. HECO's April 1989 request for proposals to develop the 500 MW geothermal cable project includes as Appendix $A$, a report by William D'Olier, a registered California geologist, who is a recognized geothermal consultant (Exhibit J). Mr. D'olier is outspoken about his concern that 
for all the time HGP-A was operating it did not prove out the magnitude of the geothermal resource in the East Rift Zone. It appears that the State dedicated its efforts to research for geothermal technology, rather than performing the necessary flow measirements and other observations. to estabiish if there is a sufficient reservoir to consistently generate 25 MW (Ormat), let alone $500 \mathrm{MW}$. He admonishes HECO to go slowly and states: "it has afforded only a meager basis for understanding the geothermal resource. The lack of detailed records of fluid production parameters, of periodic pressure-temperature-spinner surveys over the well's 3530foot perforated liner completion interval and of reservoir pressure monitoring in any offset observation hole are to be noted. This provides little context within which several perceptive and thorough studies of produced fluids chemistry can be conclusively judged ". He also states that there is a strong possibility of lava flows disrupting any geothermal installation.

HGP-A dropped in output from a rated $3 \mathrm{MW}$ to $2.45 \mathrm{MW}$ during its short operation and there was extensive seawater intrusion which could of course quench production wells. While the continally moving magma does produce steam it can also pinch off wells as happened in Iceland. A further concern is the viability of the very necessary brine reinjection has not been proven. The intruding seawater has a high silica content which causes extensive scaling of both production and reinjection wells necessitating continued drilling of new wells.

Based on this report alone no geothermal development should continue until adequate long term testing is done of the already drilled 7 wells to determine if: (1) there is a sufficient long term geothermal reservoir for the planned developments, and (2) the fluids can be practically and economically reinjected in a sound environmental manner. Just determining fluid temperatures and short term operation of one well as a basis for a 200 fold extrapolation could be disastrous.

15. Most states have an environmental policy act which is followed even during the investigation stage of a generation plant. DBED, however, has been heavy handed in its interpretation of Hawaii's statute and doesn't prepare such a report, with due consideration of public input, prior to drilling exploratory wells, or cable testing. Prior to proceeding with development we would expect a full blown environmental impact statement (EIS) to be prepared, with complete consideration and addressing of public concerns, before proceeding further. One of the principal alternatives to project development is no project at all. 
We see little evidence that these procedures which are normal for generation plant development. are being followed by HECO or DBED, in the manner we are accustomed to on the mainland. In fact we have the strong feeling that public meetings are a lip-service formality to be disposed of as quickly as possible and then to proceed on course preparing a "master plan" for development and not an EIS to determine if there should be a project at all.

One wonders if the current drilling operation has safeguards to protect life and property in the case of a blowout. Or if the level of hydrogen sulphide emissions is being controlled by such techniques as injection of hydrogen peroxide and sodium hydroxide solutions. Also if any consideraton has been given to the normal practice of directional drilling from one location to reduce land use and resulting ecological impacts.

There is considerable experience with the environmental impacts at a number of geothermal installations throughout the world, in addition to the air and water pollution aspects discussed previously. The impacts on plant life at the Geysers are described in Exhibit $K$ and in the Philippines in Exhibit L. The principal villan is boron but arsenic and hydrogen sulfide also contribute to the destruction. University of Hawaii treatises on control of native wildlife and mercury emissions in Hawaii, are described in Exhibits $M$ and $N$ respectively. The rainforest concerns are presented in articles by Professer Hampton Carson, Professer Emeritus of Genetics, John A. Burns School of Medicine, and member of the National Acemedy of Sciences (Exhibit 0 ), and by William Merwin, Pulitzer Prize-winning poet in Exhibit P.

In conclusion, this large scale geothermal proposal has all the makings of a financial and environmental disaster for the state. Work is plowing ahead and apparently there is little that can be done to change its course. Cable testing, drilling, solicitation of proposals, all proceed despite public opposition and without required environmental assessments and impact statements. 